\title{
Women and nurture in industrial societies
}

\author{
BY PENNY VAN ESTERIK \\ Department of Anthropology, York University, Room 2054, Vari Hall, 4700 Keele Street, North York, \\ Ontario M3J IP3, Canada
}

To address the subject of women and nutrition, it is necessary to work across disciplines. There is a long tradition of nutritionists and anthropologists working together in the United States, thanks to the pioneering work of Margaret Mead in this area. In Britain, the collaboration began even earlier with Audrey Richards (1932) in the 1930s. This collaboration continues today in the Economic and Social Research Council's research programme on the Nation's Diet: the Social Science of Food Choice, directed by Professor Anne Murcott. Unfortunately, in Canada it never really began. The following are some reasons why collaboration between anthropologists and nutritionists is valuable:

1. while the immediate causes of hunger and malnutrition may be related to an inadequate intake of nutrients, the basic underlying causes of hunger are rooted in the cultural system; 2. nutrition programmes and interventions are often assumed to be transportable crossculturally. This is not so. Awareness of cultural differences suggests how programmes may be adapted to fit different cultural contexts;

3 . what is considered 'edible' is culturally determined. Nutritionists need to know how food and drink are defined and categorized in the local language before undertaking any food-intake data collection;

4. nutritional methods such as dietary surveys and anthropometric assessment are inadequate for explaining reasons behind food selection or eating patterns;

5. sample selection and targeting of at-risk populations is more effective when the nutritionist has knowledge of intra-cultural diversity within a given population;

6 . both the media and policy makers can use in-depth case studies derived from anthropological fieldwork to communicate with the public about food and hunger issues;

7. knowledge of cultural factors allows for the development of culturally-appropriate messages regarding nutrition and food;

8. cultural analysis shows how food issues are interconnected with other domains such as agriculture or health; this facilitates integrating nutrition programmes with other programmes.

Nutritionists are professionals in a field with well-defined methods for evaluating nutritional status and dietary adequacy. It is unrealistic to expect nutritionists to have the motivation, need, or opportunity to study anthropology. However, nutritionists and anthropologists working together make powerful and effective teams. When we discuss topics such as women and nutrition, this collaboration is essential.

Nutritionists talk about nutrients, and both nutritionists and anthropologists talk about food and the relationship between food and health. But without careful consideration of the topics of power and gender, we may well be talking to ourselves, and not affecting the context within which women live, nurture others, and eat.

The present paper addresses the relationship between women in industrial societies, and nurture, the capacity to nourish and provide food for others. I refer generally to EuroAmerican societies dependent on industrial food systems. Such food systems provide a wide variety of highly-processed foods often produced at a distance from the consumer 
and, thus, dependent on bulk transport. Viewed historically and cross-culturally, such systems are inefficient with respect to energy used to produce the energy consumed, and expensive, contributing to differences in people's access to food. Industrial food systems have the potential to produce great amounts of food, but because the cost of producing that food is also great, the task is usually taken over by large corporations who can afford to risk more and even lose money in one part of the food system while they make money in another.

In the present paper, which draws on a number of social sciences, I would like to draw attention to the importance of examining the relationship between women and food in its broadest possible context by considering first, women and food (with a focus on individuals), gender and food (with a focus on relationships) and feminism and food (with a focus on re-orienting theory). Each conceptual category builds on the other, and the distinctions are arbitrary and heuristic. The orientation we take establishes the kinds of research questions and policy initiatives that are likely to be developed, since each operates with a different set of assumptions.

\section{WOMEN AND FOOD}

Women have a special relationship with food. They are the transmitters of cultural codes through the everyday routines of family meals. While some may accept that this special relationship with food exists for 'other' women in developing countries, or women living on the margins of global processes in inaccessible pockets of the world, the centrality of women and food in industrialized societies poses a problem for feminist analysts who see dangers in overstressing women's nurturant capacities. But nutritionists direct attention to women, recognising both their special needs and their special role as food providers within the family. Approaches to women and food discussed later include the division of labour in the food system, women's nutritional needs, and women's rights to food.

Women are food to fetus and infant, as well as the provider of food for family and others in an endless cycle of daily meal provision. Planning meals and clearing up take more time and energy and investment in social relationships than food sharing and commensality, but are seldom calculated at all in women's food work. A Swedish study estimated that time spent on domestic food preparation (shopping, cooking, and clearing up) took up about $50 \%$ more hours than were spent in paid work in all Swedish industries (Ekstrom, 1990; cited by Warde \& Hetherington, 1994). A number of social science research projects have confirmed that much of the work of food acquisition and preparation (and certainly disposal) is women's work through a division of labour that is almost universal. DeVault (1991) examines women's roles in feeding families in an American city, confirming that women carry out the tasks to ensure that families are fed culturallyacceptable meals. She views meals as organizing the central ritual of family life, documents how much of this work is invisible, and explores the influence of class on food work.

Douglas' (1972) important work on British meals was influential in North America, as several studies built on her observations on the structure of cuisine (Douglas, 1984). The work of Goode et al. (1984) in particular applied Douglas' (1972) framework to the study of meals in Italian-American households in Philadelphia, confirming the importance of ethnicity in defining food habits. Douglas' (1972) pioneering work has been followed up by Murcott (1982) in Wales and Charles \& Kerr (1988) in the city of York. These studies provide important information about the context and meaning of food and eating, and the complexity of women's relations with food. This relation has become naturalized and taken 
for granted in industrialized countries. In the household division of labour, men help women with routine cooking, provide take-away meals and barbecue (Charles \& Kerr, 1988; Warde \& Hetherington, 1994). When men cook they have yet to find a place in the female-to-female family food traditions.

A woman's identity and sense of self is often based on her ability to feed her family. As the basis of her self identity, nurturing her family may become even more important to a woman under conditions of rapid social change. At the household level, this gendered division of labour is changing only slowly as women enact their place in families and communities through food, exerting subtle and not so subtle influence.

In the professional division of labour in North America, nutrition provided women an acceptable arena in which to practice science, in addition to enhancing women's position in the domestic sphere (Apple, 1995). Nutritional science and household cooking met in North America in the development of home economics or domestic science. Domestic science aimed to replace traditional female knowledge with scientific knowledge of nutrition in order to cure the social ills of society (Shapiro, 1986). Here the power to nurture was considered strong enough to heal communities. To the domestic reform movement, '... cooking and housework were sex-linked commitments as definitive as childbearing' (Shapiro, 1986). Now women were held responsible for providing scientifically-adequate meals to their families, as well as satisfying ones. And they could be faulted by welfare bureaucracies for failing to do so. In 1904, increasing numbers of Chicago mothers were applying for aid as a result of runaway husbands. The solution was the provision of cooking classes for girls (Apple, 1995).

Women are usually mentioned in the nutrition literature as a risk group or a target group for needed interventions rather than as gatekeepers of family health. Nutritionists focus attention on the special nutritional needs of women. A recent textbook on the nutritional concerns of women examines diet-related risk factors for women: osteoporosis, anaemias, obesity, eating disorders, cardiovascular disease, reproductive issues (premenstrual syndrome, contraception, pregnancy, lactation) and women's cancers. In this paradigm, women are at risk, and nutrition education may be proposed to alter their relationship with food. If children are at risk, women are instructed on how to improve their diets as well. This message has been well received; women in Charles \& Kerr's (1988) study felt they had to teach their children to eat properly. But community nutritionists have seldom made full use of social science work demonstrating the systematic nature of eating habits. People are attached to the structure of their meals and the pattern of meals throughout the week and year. But attachments are stronger at some points than others; thus, people who want to change food habits would benefit from learning where the weak points in the system are located (Murcott, 1988).

The recent International Congress of Nutrition (1993) World Declaration and Plan of Action for Nutrition is very sensitive to the importance of women as agents and beneficiaries in the food system. This document explicitly recognizes that nutritional wellbeing is hindered by the continuation of social, economic and gender disparities and discriminatory practices and laws: 'All forms of discrimination including detrimental traditional practices against women must be eliminated in accordance with the 1979 Convention on Elimination of all forms of Discrimination Against Women'.

Vulnerability to malnutrition is greater for girls and women who may be discriminated against in access to food, and whose nutritional needs are higher during pregnancy and lactation. An inadequate diet can lead to anaemia and stunting, contributing to complications in childbirth and underweight babies. Insufficient calcium can lead to osteoporosis. The World Bank (1993) supports cost-effective interventions including 
adequate nutrition for women, particularly for vulnerable groups, and provides an economic rationale for investing in women's health, pointing out the multiple pay-offs for family, community and national economy. It is efficient and equitable to meet the nutritional needs of women. As early as 1919, legal protection for women workers was enacted through the International Labour Organization to protect motherhood, including maternity entitlements and lactation breaks.

'The nutritional status of a woman (current and past) is an important determinant of the ease with which she will conceive and carry an infant to term, the likelihood that she and the infant will survive and emerge from the birth in good health, and her capacity to breastfeed successfully' (Leslie, 1995). While this statement refers to Third World women, the logic extends to women in industrial societies. Leslie (1995) argues that women have been overtargeted by nutrition interventions. Some interventions for pregnant and lactating women operate as if women need to be fed for the sake of their children. The International Congress of Nutrition (1993) Declaration confirms that women's nutritional needs should be met not simply because they are meal providers for others and producers of food, but because they are inherently entitled to adequate nutrition in their own right as individuals. For women to provide the necessary care and to nurture others, priority must be given to enhancing the legal and social status of women from birth onwards, assuring them of respect and equal access to caring, education, training, land, credit, equity in wages and remuneration and other services, including family planning services, and empower them economically so that they have better control over the family resources' (International Congress of Nutrition, 1993).

\section{GENDER AND FOOD}

Gender and food stresses the relation between men and women, and how food practices reflect and shape those relation. This approach stresses the construction of masculinity and femininity in specific cultural and historical settings. Relationships of gender inequality, if they exist, will be exacerbated in the domain of food. Both nutritionists and anthropologists work within gendered contexts when they study people's relation with food in industrial societies. Neither nutritionists nor anthropologists are quite comfortable dealing with gender inequality and food: nutritionists, because gender analysis is not part of their training, and feminist anthropologists, because they are not willing to regard women as passive victims who exist to nurture others.

Women's rights to food within their own households are not always protected even in Euro-American societies, as the many studies of intra-household food distribution show (cf. Van Esterik, 1985; Rogers \& Schlossman, 1990). However, the fact that women and girls often eat last and least can be analysed from a gender perspective. Women may be denied food in spite of the fact that food processing, preparation and consumption are their responsibility. In Canada, this is more likely to occur in immigrant families in which girls are not valued in their country of origin.

Much more common is the pattern of women denying themselves food either because it is in short supply and the needs of their families take precedence over their own, or because they want to maintain a slim figure. Charles \& Kerr (1988) document this in northern England where women provided food to refuel their men and help their children grow, but denied food to themselves. Women may not cook a meal for themselves when they are alone, or they may cook in a rule-breaking manner to provide comfort foods denied themselves on other occasions. In poor American households, Fitchen (1988) found that women may eat only starches without the meat or vegetables provided for the rest of 
the family. They may lick the pots or finish food left on their children's plates; but they know hunger.

Women's role in meal provision is a symbolic as well as a material task. In many EuroAmerican societies, a home-cooked hot meal symbolizes hearth, home, and domestic relations between men and women. Those meals are probably cooked according to their husband's tastes not their own. In ethnically-mixed marriages, this means learning their husband's tastes across ethnic and possibly class lines: 'Part and parcel of intimacy is knowledge of others' personal idiosyncrasies' (Murcott, 1993).

Perceived failure of performance of food-related tasks can trigger violence against women. The time-boundedness of food work exacerbates the potential for abuse. Women are expected to prepare good food that men like, on time and in the manner they prefer, regardless of budget. Lack of money for food (money that should come from men in some cases) is not a sufficient excuse (Ellis, 1983; Murcott, 1983). Women may literally lose their appetites when in abusive relationships. But women will no doubt recall the foodbased revenge that can be exacted against men who abuse them or drink too much. For example, Weismantel (1988) writes of Andean women who feed their hung-over husbands with excessive amounts of food they cannot refuse, with predictably uncomfortable results. We hear very little about abuse in relation to food and need more interdisciplinary research to uncover the relationships between domesticity and deference. Although women have the illusion of control over household meals, men exert a strong influence over women's household practices. It is, thus, counterproductive to address nutrition education messages to women without consideration of the constraints under which they operate.

There is a special pleasure in consuming foods in the public domain, a sense of occasion absent from private meals. Women in particular enjoy dining out, as they may be doubly pleasured, first by not having to cook for men, and second, by having men serve them. Career women may use restaurants more as a way of contracting out of domestic responsibilities (Finkelstein, 1989).

In industrial societies, women's relation to food is problematic because of the linkage between food and body image in diet-conscious women. Anorexia and other eating disorders of women are increasing in prevalence in Euro-American societies. Discomfort with their bodies is becoming commonplace even for young girls. Psychological research confirms the commonly-held perception that women who eat smaller meals are viewed as more feminine, better looking and more concerned about their appearance (Chaiken \& Pliner, 1987). In the northern England research of Charles \& Kerr (1988), women viewed food as a treacherous friend; 'they desired it for the pleasure it gave but denied themselves the pleasure because of the unacceptable weight gain that might result if they indulged themselves. At the same time, it was a comfort, a support in time of need...'. The complex of stress, depression and compulsive eating among women is also well documented (Chernin, 1981, 1985). Rage leaves women hungry for food and justice.

How do our relation with food develop? Clearly, food socialization must be strongly linked with gender. In a study of American 10-year-old children, Roos (1995) found that food is a symbol for friendship and connection for girls, but a means to express dominance and competition for boys. In some societies, children are socialized to share from a very early age, particularly with their younger siblings. Food socialization is critically important for understanding gender-related food ideologies.

Food ideologies are part of cultural domains even farther removed from women and nutritional issues. For example, food relations are deeply embedded in English literature, as Kiell's (1991) substantial bibliography on the subject confirms. Dickens' depiction in his novels of nurturing children is a well-known example (Burgan, 1991). Food ideologies are 
reflected in our literature and our language: 'For the Elizabethans it was almost cliché to compare her complexion with whipped cream, her cheeks with ripening peaches and her lips with red cherries. Similarly, the Middle-East has identified her with a veritable banquet of exotic delights: her cheeks are pomegranates; her lips luscious grapes; her breasts apples smoothed with myrrh...' (Patnaik, 1988). Disentangling food from gender and sexuality is a near impossible but delightful task.

In discussing gender and food, more contradictions arise. It is not surprising that we resist making the link between women and food too closely. For it is a troubled relationship, and one that will draw feminist fire if it is not analysed with care. Women's association with food is not a simple one, and cannot be reduced to the notion that the ability to nurture is an essential quality of women. Fears of essentializing women and reducing them to food providers has kept many from delving into this relationship. Even with careful interdisciplinary research on this topic, we will not overcome contradiction and paradox. Perhaps the discipline of anthropology is a little more comfortable with contradiction and paradox than that of nutrition, but a closer examination of women and nurture raises new questions for both disciplines. Thus, we shift attention to a consideration of food and feminist theory.

\section{FOOD AND FEMINISM}

Feminist theory is broadly based in the social sciences and humanities, and informs the women's movement; that is, it should be the guiding influence behind activities to support gender equality. Some nutritional and food research on women's issues is beginning to be subjected to a feminist critique and represented in a new light, raising new questions. But generally, nutritionists have had little professional interest in feminist theory, and feminists have ignored food (with a few exceptions, particularly on the issue of eating disorders).

Breaking down oppositional thinking is an important part of feminist theoretical reorientation. It opens the door to re-integrating everyday practices and objective scientific knowledge. Cooking as 'thoughtful practice' (Curtin \& Heldke, 1992) blends theory and practice, body and mind, and reflects the way women experience food, not as nutrients, but as nurture.

Curtin \& Heldke (1992) argue that the study of food and eating has been marginalized because of Western binary logic which first separates and then gives precedence to mind over body, theory over practice, abstract over concrete, object over subject, public over private, reason over emotion, among others. Further, food and eating, as household practices, have been seen as women's work and undervalued by society.

Eating and cooking break down these oppositions. But our disciplinary borders keep us in separate boxes defined by these oppositions. Murcott (1993) notes that in industrialized societies, particularly in Britain, the medical and gastronomic are separated, and both further separate the professional and expert from the laity. It is social science fieldwork that exposes the knowledge and practice of the 'laity' with regard to food selection. Women absorb the nutritional expert's orientation to and vocabulary of food, ignoring taste and emotional enjoyment of food (Murcott, 1993).

Women are both vulnerable and powerful, victimized and empowered through food. At first glance, linking food and women furthers the association of women with the ability to nurture, the domestic sphere and social reproduction. Focusing on food reminds us that ethnocentric oppositions such as production and reproduction, public and private and other such inappropriate dichotomies are a Western legacy of blinkered binary thinking. Food practices entail both productive and reproductive work, public and private spaces, and are 
part of both the formal and informal economy (both/and not either/or). The special case of breast-feeding, for example, makes this clearer, and is an excellent example of how feminist theory can be marshalled in support of breast-feeding (Van Esterik, 1994).

Women's bodies are simultaneously the means of production and reproduction, producing babies and breast milk. This is both productive and reproductive work and is both a public and a private act. Breast-feeding has been approached as a child's right to breast milk; a child's right to be breast-fed; a woman's right to breast-feed; and enabling and empowering women to breast-feed. By focusing on empowering women to breast-feed, we still address women's rights since the improvement of women's social and economic status is necessary for supporting breast-feeding. Other food practices confound the dichotomy between production and reproduction, public and private. The task of preparing meals cannot be reduced to a private act of social reproduction when the food produced may be redistributed in community potluck dinners or in soup kitchens. Are these public or private acts?

\section{CONCLUSION}

In the previous sections, I distinguished three orientations to food. Women and food stresses the division of labour, nutritional needs, and the rights of individuals, using an approach to nutritional issues based on efficiency. Gender and food draws attention to the construction of masculinity and femininity, stressing gender inequalities related to food, and might be considered an equity approach. Feminism and food calls for the breaking down of oppositional thinking separating different ways of knowing about and experiencing food. This theoretical orientation would require a new vocabulary. A good beginning would be to develop the analytical potential of the terms nurture and commensality, and to base research and policy questions around them.

Nurture and the ability to nurture are loaded words, particularly for feminists who see biological determinism rearing its ugly head. Nurture implies caring for, caring about, and acting with (relational) rather than acting on. There is a custodial feel to nurture, one that is intimately connected with personhood. Nurture embraces both science and art. As such, it is not reducible to technique or technology. Neither can replace nurture or care. We spend our time and money and brain power on the search for techniques and technology, rather than on the relationships that foster nurturing. Yet the failure to nurture has a profound effect on individuals and communities. Nurture cannot be manipulated. Like grace, it is a gift bestowed but not measured. Charity, food charity in particular, is measured, and can be compromised, as we have seen in the case of food aid, or soup kitchens.

The power is nurture is an unexamined and undervalued power. But it is not without coercive features. The power to nurture others is also power over others, and, like any power relationship, can be abusive. Until women have full equality, then whoever depends on women for food will be vulnerable to manipulation through food, and could exert pressure on women through food. Family meals are important localities for such manipulation. Consider also women's involvement in and pleasure derived through food charities such as food banks, soup kitchens, and meals on wheels, a subject requiring further study.

Commensality, according to the Oxford English Dictionary, refers to eating at the same table, and by implication, sharing food. Commensality is a particular relationship between individuals, groups and the food they consume. But the sharing of food is also a paradigmatic moment with broader implications. How do these moments of sharing frame more general political and ethical questions about the right to food and the responsibility to 
feed others? This term draws together concerns about food aid, food charity, trade agreements, and commercial agriculture, among others; and places hunger, poverty, and scarcity in the context of global food systems, suggesting that there are intimate connections between local and global commensality.

Nurture and commensality build from the concept of care. The vocabulary of care is not a vocabulary familiar to most nutritionists and anthropologists in their professional research. But recently, care has been drawn into the vocabulary of international nutrition. The United Nations International Children's Emergency Fund has recognized that food security and primary health care are not adequate to account for child survival. The challenges in working with such a concept are just beginning to be explored (Jonsson, 1995).

Once again, we are challenged to cross disciplinary boundaries because care is not a simply-measured variable. Gilligan (1982) argued for an activities-based approach to the ethics of care, stressing skilled practices embedded in social relationships rather than personality characteristics based on gender. But the fact remains that most sociallynecessary caring work is undervalued and unmeasured as unpaid women's work. Caregiving and nurturing others falls somewhere between the work of sustenance and service (DeVault, 1991). Past research on care has been linked with long-term illness, disability and ageing. Care-givers nurture others, but at a cost to themselves, suppressing conflict and contradictions around the experience. In contrast, caring through food is part of daily routines, emergency or crisis responses, and heightened rituals of commensality. How we develop methods for combining what is measurable (nutrients, food prices, diet assessments) with what is immeasurable (nurture, commensality, care) will be a continuing challenge that should draw nutritionists and anthropologists closer together in the future.

I would like to thank Jennifer Welsh, Pauline Costello and Terri Aihoshi for assistance in the preparation of this paper.

\section{REFERENCES}

Apple, R. (1985). Science gendered: Nutrition in the United States, 1840-1940. In The Science and Culture of Nutrition. Wellcome Institute Series in the History of Medicine, pp. 129-154 [H. Kamminga and A. Cunningham, editors]. Amsterdam: Rodopi.

Burgan, M. (1991). Bringing up by hand: Dickens and the feeding of children. Mosaic 24, 69-88.

Chaiken, S. \& Pliner, P. (1987). Women, but not men, are what they eat: the effect of meal size and gender on perceived femininity and masculinity. Personality and Social Psychology Bulletin 13, 166-176.

Charles, N. \& Kerr, M. (1988). Women, Food and Families. Manchester: Manchester University Press.

Chernin, K. (1981). The Obsession: Reflections on the Tyranny of Slenderness. New York: Harper and Row.

Chernin, K. (1985). The Hungry Self. New York: Harper and Row.

Curtin, D. \& Heldke, L. (editors) (1992). Introduction. In Cooking, Eating, Thinking: Transformative Philosophies of Food. Bloomington and Indianapolis: Indiana University Press.

DeVault, M. (1991). Feeding the Family. Chicago: University of Chicago Press.

Douglas, M. (1972). Deciphering a meal. Daedalus 101, 61-81.

Douglas, M. (editor) (1984). In Food in the Social Order. New York: Russell Sage Foundation.

Ellis, R. (1983). The way to a man's heart: food in the violent home. In The Sociology of Food and Eating, [A. Murcott, editor]. Aldershot, Hants: Gower Publishing.

Finkelstein, J. (1989). Dining Out. New York: New York University Press.

Fitchen, J. (1988). Hunger, malnutrition and poverty in the United States: some observations on their social and cultural context. Food and Foodways 2, 309-333.

Gilligan, C. (1982). In a Different Voice. Cambridge, MA: Harvard University Press.

Goode, J., Curtis, K. \& Theophano, J. (1984). Meal formats, meal cycles, and menu negotiations in the maintenance of an Italian-American community. In Food in the Social Order, [M. Douglas, editor]. New York: Russell Sage Foundation. 
International Congress of Nutrition (1993). World Declaration and Plan of Action for Nutrition. Rome: FAO. Jonsson, U. (1995). Ethics and child nutrition. Food and Nutrition Bulletin 16, 293-299.

Kiell, N. (1991). Food in literature: a selective bibliography. Mosaic 24, 211-263.

Leslie, J. (1995). Improving the nutrition of women in the Third World. In Child Growth and Nutrition in Developing Countries, pp. 117-138 [P. Pinstrup Anderson, D. Pelletier and H. Aldermanl, editors]. Ithaca, New York: Cornell University Press.

Murcott, A. (1982). On the social significance of the 'cooked dinner' in South Wales. Social Science Information 21, 677-695.

Murcott, A. (1983). Cooking and the Cooked: a note on the domestic preparation of meals. In The Sociology of Eating, [A. Murcott, Editor]. Aldershot, Hants: Gower Publishing.

Murcott, A. (1988). Sociological and social anthropological approaches to food and eating. World Review of Nutrition and Dietetics 55, $1-40$.

Murcott, A. (1993). Talking of good food: an empirical study of women's conceptualizations. Food and Foodways 5, 305-318.

Patnaik, E. (1988). The succulent gender: eat her softly. In Literary Gastronomy, pp. 59-74 [D. Bevan, editor]. Amsterdam: Rodopi.

Richards, A. (1932). Hunger and Work in a Savage Tribe. London: Routledge.

Rogers, B. L. \& Schlossman, N. (1990). Intra-Household Resource Allocation. Tokyo: United Nations University.

Roos, G. (1995). Relationship between food and gender among fourth-grade children. Crosscurrents 7, 97-108. Shapiro, L. (1986). Perfection Salad: Women and Cooking at the End of the Century. New York: Henry Holt. Van Esterik, P. (1985). Intra-family food distribution: its relevance for maternal and child health. In Determinants of Young Child Feeding and Their Implications for Nutritional Surveillance. Cornell Intemational Nutrition Monograph Series: no. 14 [M. Latham, editor]. Ithaca, New York: Cornell.

Van Esterik, P. (1994). Breastfeeding and feminism. International Journal of Gynaecology and Obstetrics 47, Suppl, , 41-54.

Warde, A. \& Hetherington, K. (1994). English households and routine food practices: A research note. The Sociological Review 42, 758-778.

Weismantal, M. (1988). Food, Gender and Poverty in the Ecuadorian Andes. Philadelphia: University of Pennsylvania Press.

World Bank (1993). World Development Report 1993: Investing in Health. New York: Oxford University Press. 